\title{
Increase methylmercury accumulation in Arabidopsis thaliana expressing bacterial broad-spectrum mercury transporter MerE
}

\author{
Yuka Sone ${ }^{1}$, Ryosuke Nakamura ${ }^{1}$, Hidemitsu Pan-Hou${ }^{2}$, Masa H Sato ${ }^{3}$, Tomoo Itoh ${ }^{1}$ and Masako Kiyono ${ }^{\text {* }}$
}

\begin{abstract}
The bacterial merE gene derived from the Tn21 mer operon encodes a broad-spectrum mercury transporter that governs the transport of methylmercury and mercuric ions across bacterial cytoplasmic membranes, and this gene is a potential molecular tool for improving the efficiency of methylmercury phytoremediation. A transgenic Arabidopsis engineered to express MerE was constructed and the impact of expression of MerE on methylmercury accumulation was evaluated. The subcellular localization of transiently expressed GFP-tagged MerE was examined in Arabidopsis suspension-cultured cells. The GFP-MerE was found to localize to the plasma membrane and cytosol. The transgenic Arabidopsis expressing MerE accumulated significantly more methymercury and mercuric ions into plants than the wild-type Arabidopsis did. The transgenic plants expressing MerE was significantly more resistant to mercuric ions, but only showed more resistant to methylmercury compared with the wild type Arabidopsis. These results demonstrated that expression of the bacterial mercury transporter MerE promoted the transport and accumulation of methylmercury in transgenic Arabidopsis, which may be a useful method for improving plants to facilitate the phytoremediation of methylmercury pollution.
\end{abstract}

Keywords: Bacterial broad-spectrum mercury transport; MerE; Methylmercury; Phytoremediation

\section{Introduction}

Mercury pollution is still a worldwide problem in environments because of natural events and human activities such as coal burning, industrial use and gold-mining activities (Harada 1995). Metallic and ionic form of mercury can accumulate in sediments, where they are readily converted to highly toxic methylmercury by microbes (Barkay et al. 2003). Clinical investigations have shown that methylmercury is the principal form of mercury that accumulated in fish and biomagnifies in their consumers, causing severe neurodegenerative symptoms (Harada 1995). The severe adverse effects of this contaminant mean there is an urgent need to develop an effective and affordable technology to facilitate its removal from the environment.

Phytoremediation refers to the use of green plants in the removal of environmental pollutants, which is

\footnotetext{
* Correspondence: kiyonom@pharm.kitasato-u.ac.jp

${ }^{1}$ Department of Public Health and Molecular Toxicology, School of Pharmacy, Kitasato University, 5-9-1 Shirokane, 108-8641 Minato-ku, Tokyo, Japan Full list of author information is available at the end of the article
}

recognized as a cost effective, sustainable, and environmentally friendly approach that has many advantages during the large-scale clean-up of contaminated sites (Clemens et al. 2002; Kramer 2005; Malik 2004; Ruiz and Daniell 2009; Salt 1998). In recent studies, Meager et al. engineered bacterial mer operons such as MerA (mercuric reductase) to reduce reactive mercuric ions to volatile and relatively inert monoatomic $\mathrm{Hg}(0)$ vapor, and MerB (organomercurial lyase) to degrade methylmercury to mercuric ions into plants, thereby remediating methylmercury contamination (Meagher and Heaton 2005). Plants such as cottonwood trees (Lyyra et al. 2007) and tobacco (Heaton et al. 2003) have been modified to express either MerB or both MerB and MerA, which convert methylmercury to mercuric ions or mercury vapor, respectively. The disadvantage of this approach is that elemental mercury $\operatorname{Hg}(0)$ is released into the environment, where it accumulates and can eventually be converted into highly toxic methylmercury. To help address this environmental problem, a new methylmercury remediation method is required to 
replace the $m e r A$-mediated mercury reduction mechanism so plant cells can accumulate methylmercury from contaminated sites without releasing mercury vapor into the ambient air.

In general, rehabilitation of metal-contaminated soils by plants requires a long time for the purification process to be completed. McGrath and Zhao reported that several months were required to reduce the mercury content by half in contaminated soils (McGrath and Zhao 2003). The expression of mercury transporter in the plant may provide a means of improving mercury uptake, thereby shortening the purification completion time. In a previous study, we demonstrated for the first time that the MerE protein encoded by $\mathrm{pE} 4$ is localized in the membrane cell fraction and that MerE is a novel, broad-spectrum mercury transporter, which governs the transport of $\mathrm{CH}_{3} \mathrm{Hg}(\mathrm{I})$ and $\mathrm{Hg}(\mathrm{II})$ across bacterial cytoplasmic membranes (Kiyono et al. 2009; Sone et al. 2010).

The current study evaluated the feasibility of engineering transgenic Arabidopsis plants to express bacterial broad-spectrum mercury transporter, MerE and its potential use in the phytoremediation of methylmercury pollution. This study showed that expression of MerE promoted the transport and accumulation of methylmercury in transgenic Arabidopsis. Enhanced methylmercury accumulation mediated by MerE represents one way for improving plants to be more suitable for use in phytoremediation of methylmercury pollution.

\section{Materials and methods}

\section{Materials and growth conditions}

Table 1 shows the Escherichia coli (E. coli), Arabidopsis thaliana (A. thaliana)-cultured cells and plasmids used in this study. E. coli XL1-Blue was grown at $37^{\circ} \mathrm{C}$ in Luria-Bertani (LB) medium and used for routine plasmid propagation. When necessary, the medium was supplemented with $25 \mu \mathrm{g} / \mathrm{mL}$ kanamycin. Suspension-cultured A. thaliana cells were maintained in Murashige and Skoog (MS) medium on a rotary shaker at $22^{\circ} \mathrm{C}$ with continuous white light and sub-cultured once a week. $A$. thaliana ecotype Columbia was used for the plant transformations. The seeds produced were germinated and grown on jiffy-7 peat pellets, whereas the surfacesterilized seeds were sown onto MS agar plates. The plants were grown in an environmental growth chamber (Sanyo, Tokyo, Japan) at $22^{\circ} \mathrm{C}$ in long-day (16 h light/ $8 \mathrm{~h}$ dark) conditions.

\section{Enzymes and reagents}

The restriction enzymes, the DNA ligation kit and Taq polymerase were obtained from Takara Shuzo Corp. (Kyoto, Japan). Analytical reagent grade mercury was purchased from Wako Chemicals (Tokyo, Japan).

\section{Plasmid construction}

The recombinant plasmids and oligonucleotide primers used in this study are described in Table 1 and Table 2, respectively. The plasmid pE18 that carried the $g f p$-merE fusion gene was constructed in pUC18 as follows. A $0.23 \mathrm{~kb}$ fragment containing merE was PCR-amplified using the primers U-Bgl-merE and L-Kpn-merE, which contained BglII and KpnI sites. The pE4 plasmid (Kiyono et al. 2009) was used as a template. After digestion the PCR product with BglII and KpnI, the fragment was cloned into the corresponding sites in CaMV35SsGFP(S65T)-NOS3' (Uemura et al. 2004) and sequenced, and then designated as pE18.

The plasmid pMAE2 that carried the merE gene was constructed in pMAT137 (Matsuoka and Nakamura 1991) as follows. The primers U-Not-merE and L-XbamerE were used to amplify the merE region $(0.23 \mathrm{~kb})$ with pE18 as a template. After digestion the PCR products with NotI-XbaI, the fragment was cloned into the NotI-XbaI sites of pMAT137. The cloned fragment was sequenced and the resulting plasmid was designated as pMAE2.

Table 1 Strains and plasmids used in this study

\begin{tabular}{|c|c|c|}
\hline Strains and plasmids & Description of relevant features(s) & Reference or source \\
\hline \multicolumn{3}{|l|}{ Strains } \\
\hline E.coli XL1-Blue & $\begin{array}{l}\text { recaAl endAl gyrA96 thi hsdR17 supE44 relAl } \\
\text { lac/[F::Tn/OproAB + lacla lacZM15 traD36 }\end{array}$ & (Bullock et al. 1987) \\
\hline Arabidopsis thaliana suspension-cultured cells & Alex & (Ueda et al. 2001) \\
\hline \multicolumn{3}{|l|}{ Plasmids } \\
\hline $\mathrm{pE} 4$ & meR-o/p-merE in pKF19k & (Kiyono et al. 2009) \\
\hline pMAT137 & $\begin{array}{l}\text { None: binary expression vector with a CaMV35S promoter } \\
\text { produced by tandem duplication of the enhancer sequence }\end{array}$ & (Matsuoka and Nakamura 1991) \\
\hline CaMV35S(S65T)-NOS3' & GFP in pUC18 & (Uemura et al. 2004) \\
\hline $\mathrm{pE} 18$ & GFP-MerE in pUC18 & This study \\
\hline pMAE2 & MerE in pMAT137 & This study \\
\hline
\end{tabular}


Table 2 Oligonucleotide primers used in this study

\begin{tabular}{ll}
\hline Primer & Oligonucleotide $\left(\mathbf{5}^{\prime} \rightarrow \mathbf{3}^{\prime}\right)$ \\
\hline U-Bgl-merE & GAAGATCTATGAACGCCCCTACAAA \\
L-Kpn-merE & GGGGTACCTCATGATCCGCCCCGGAA \\
U-Not-merE & AAGGAAAAAAGCGGCCGCATGAACGCCCCTGACAAACT \\
L-Xba-merE & GCTCTAGATCATGATCCGCCCCGGAAGG \\
U-321NPTII & ATTGAACAAGATGGATTGCA \\
L-1109NPTII & GAAGAACTCGTCAAGAAGGC \\
$\beta$-ACT-Fd & CAACTGGGACGACATGGAGA \\
$\beta$ - ACT-Rv & GATCCACATCTGCTGGAAGG \\
\hline
\end{tabular}

\section{Confocal laser scanning microscopy}

GFP-fused proteins were transiently expressed in $A$. thaliana suspension-cultured cells using a published method (Uemura et al. 2004). Cells transformed with pE18 were viewed without fixation under an Olympus BX60 fluorescence microscope, which was equipped with a Model CSU10 confocal scanner (Yokogawa Electric) (Nakano 2002) and a Zeiss LSM510 META or LSM5 PASCAL microscope, which were equipped with green $\mathrm{HeNe}$ and argon lasers.

\section{Transformation of plants and confirmation of transgenic plants}

The pMAE2 plasmid was introduced into Agrobacterium tumefaciens (A. tumefaciens) via electroporation (Mozo and Hooykaas 1991). A. tumefaciens was grown at $25-28^{\circ} \mathrm{C}$ in $\mathrm{LB}$ medium added with $25 \mu \mathrm{g} / \mathrm{mL}$ kanamycin and employed for the transformation of $A$. thaliana. A. thaliana ecotype Columbia plants were transformed using the floral dip method (Clough and Bent 1998) by Inplanta Innovations Inc. (Kanagawa, Japan). The progeny seedlings were selected on MS medium containing $50 \mathrm{mg} / \mathrm{L}$ kanamycin. The third generations of merE transgenic plants $\left(\mathrm{T}_{3}\right)$ were used for all experiments described in this paper.

Plant genomic DNA was isolated from transformed and untransformed leaves using the FTA Kit (GE Healthcare, Buckinghamshire, England) in accordance with the manufacturer's instructions. The target genome DNA was amplified using specific primers, i.e., U-Not-merE and L-Xba -merE for merE, according to the manufacturer's instructions (Table 2). The primers U-321NPTII and L1109 NPTII were used to amplify NOS-NPTII in each PCR reaction, as control (Table 2 ). The PCR products were separated on $2 \%$ agarose gels and visualized by ethidium bromide staining.

Quantitation of mRNA levels by reverse transcription PCR Total RNA was extracted from cells using an RNeasy Plant Mini Kit (Qiagen, CA, USA), according to the manufacturer's instructions. The Superscript First-strand
Synthesis System for reverse transcription PCR (Life Technologies, CA, USA) was used to prepare singlestranded cDNA. The target cDNAs were amplified using specific primers, i.e., U-Not-merE and L-Xba-merE to merE, according to the manufacturer's instructions. The primers $\beta$-ACT-Fd and $\beta$-ACT-Rv were used to amplify $A C T 1$ in each PCR reaction as controls (Table 2). The PCR products were separated on $2 \%$ agarose gels and visualized by ethidium bromide staining.

\section{Subcellular fractionation of Arabidopsis tissues}

To generate roots, surface-sterilized $A$. thaliana seeds were germinated in sterile MS liquid medium with $100 \mathrm{rpm}$ shaking using a rotary shaker in dark conditions. The roots of 14-day-old plants were homogenized in a grinding buffer, which contained $50 \mathrm{mM}$ Tris- $\mathrm{HCl}$, pH 7.5, $250 \mathrm{mM}$ sorbitol, $5 \mathrm{mM}$ EDTA, $5 \mathrm{mM}$ EGTA, $1 \mathrm{mM}$ dithiothreitol, and $100 \mu \mathrm{M}$ p-(amidinophenyl) methanesulfonyl fluoride hydrochloride (APMSF). The homogenate was filtered through four layers of Miracloth (EMD Biosciences, Darmstadt, Germany), and centrifuged at $10,000 \times g$ for $10 \mathrm{~min}$. The supernatant was centrifuged at $100,000 \times g$ for $30 \mathrm{~min}$ and the precipitate was then suspended in the grinding buffer.

\section{SDS-PAGE and immunoblotting}

Proteins were separated by SDS-PAGE and transferred to an Immobilon-P membrane (Millipore, Billerica, USA). After blocking with de-fatted milk, the membrane filter was incubated with rabbit anti-MerE polyclonal antibody (Kiyono et al. 2009). The membranes were washed and reacted with peroxidase-conjugated anti-rabbit IgG antibody (Sigma Aldrich, MO, USA). Anti-MerE polyclonal and peroxidase-conjugated anti-rabbit IgG antibodies were used at a dilution of 1:3,000. Chemiluminescent reagents ECL (GE Healthcare, Chalfont St Giles, UK) were used to detect antigens.

\section{Mercury accumulation}

$\mathrm{T}_{3}$ transgenic plants were cultured in MS gellan gum plates with different concentrations of $\mathrm{HgCl}_{2}$ or $\mathrm{CH}_{3} \mathrm{Hg}$ $\mathrm{Cl}$ for 2 weeks at $22^{\circ} \mathrm{C}$. After treatment with $10 \mu \mathrm{M}$ $\mathrm{HgCl}_{2}$ or $0.3 \mu \mathrm{M} \mathrm{CH} \mathrm{CH}_{3} \mathrm{HgCl}$, the total amount of mercury accumulated by an entire plant was determined as follows, using 60 plants in total. Entire plants samples were digested with a concentrated acid mixture (nitric acid: perchlonic acid $=4: 1$ ) for $4 \mathrm{~h}$ at $90^{\circ} \mathrm{C}$ and their total cellular mercury contents were measured using an atomic absorption spectrometry analyzer HG-310 (Hiranuma, Japan). The standard deviation of the measurements was less than $10 \%$. 


\section{Mercury resistance}

The sensitivities of $T_{3}$ transgenic plants to mercury were tested using the following method. The sterilized seeds from wild-type and transgenic plants were aligned in a horizontal array of MS gellan gum plates, which contained $5 \mu \mathrm{M} \mathrm{HgCl}_{2}$ or $0.3 \mu \mathrm{M} \mathrm{CH} \mathrm{CH}_{3} \mathrm{HgCl}$, where they the seeds germinated and grew vertically. The root lengths of the seedlings were measured after 2 weeks' cultivation at $22^{\circ} \mathrm{C}$.

\section{Statistical analysis}

Data analysis was performed using the statistical tools (Student's t-test) of Microsoft Excel software.

\section{Results}

Cellular localizations of GFP-MerE in suspension-cultured plant cells

To determine the subcellular localization of GFP-fusion proteins in suspension-cultured plant cells, GFP-tagged MerE was expressed transiently (Figure 1A) and its fluorescence was visualized by confocal laser scanning microscopy (Figure 1B). GFP-MerE was detected primarily in the endoplasmic reticulum (Closed arrowheads in Figure 1B), but some fusion proteins were detected in the plasma membrane (Open arrowheads in Figure 1B).

\section{Expression of MerE in transgenic plants}

The PCR-amplified merE DNA fragment was subcloned into a binary vector, pMAT137, to generate the plasmid pMAE2 (Figure 2A). The plasmid was transformed into A. thaliana ecotype Columbia via Agrobacterium-mediated gene transfer (Clough and Bent 1998). Eleven merE independent transgenic lines were obtained by selection using MS medium containing $50 \mathrm{mg} / \mathrm{L}$ kanamycin. The MerE transformants exhibited no distinctive phenotypes.
For instance, the MerE transgenic plants had an equally normal growth as wild-type Arabidopsis. Six of eleven merE transgenic lines (lines E2, E3, E4, E5, E6, and E7) were selected for further studies. To confirm the presence of the merE transgene in the transgenic plants, total genomic DNA was extracted from the mature leaves of $\mathrm{T}_{3}$ progeny, and the regions of the introduced merE fragments were amplified using the genomic DNA as a template. As expected, $0.23 \mathrm{~kb}$ PCR fragment was detected in the merE (lines E2, E3, E4, E5, E6 and E7) when U-Not-merE/L-Xba-merE were used as PCR primers (Figure 2B). The expression levels of merE in plants were determined by reverse transcription-PCR (RT-PCR). The total RNA was isolated from leaves and specific primers were used to detect merE and Actin mRNA. The merE mRNA was detected in all transformants tested (Figure 2C). There was no significant difference in the mRNA levels of the individual transgenic lines, so the E2 transgenic plant was selected for further studies.

The expression levels of MerE protein were measured in transgenic plants (lines E2) by immunoblot analysis using a polyclonal anti-MerE antibody, which was prepared in a previous study (Kiyono et al. 2009). A novel protein band of $8 \mathrm{kDa}$, which reacted specifically with the anti-MerE antibody, was identified in the crude cell extract and crude membrane fraction from transgenic plants (Figure 3, lane 1\&3), whereas no protein band reacted with anti-MerE antibody was detected in the soluble fraction (Figure 3, lane 2). The protein size was consistent with the size predicted from the translation of the DNA sequence of the merE gene. These results demonstrated that the merE gene in transgenic plants was transcribed and translated into proteins with molecular mass of $8 \mathrm{kDa}$, which were probably located in the membrane fraction.
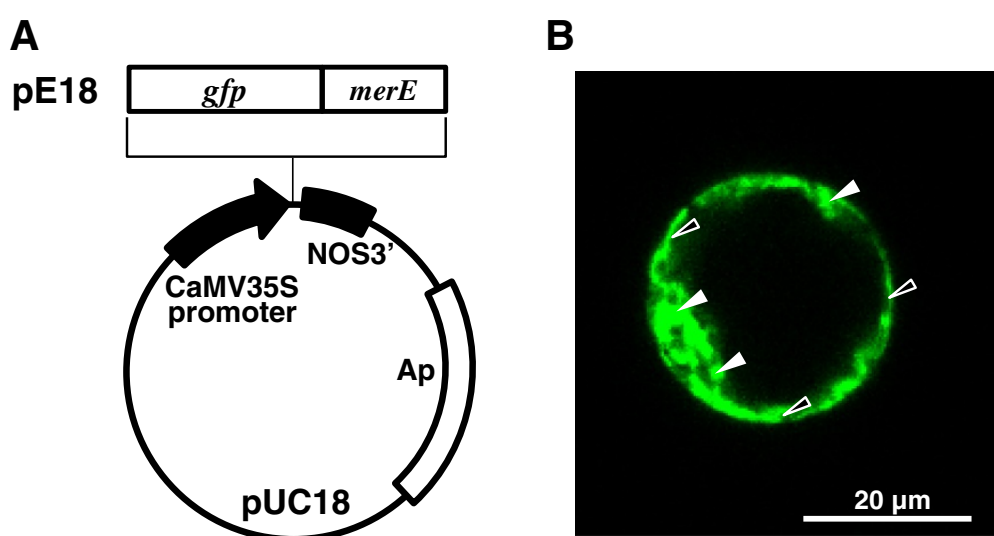

Figure 1 Construction of $g f p$-merE fusion plasmid (A) and cellular localization of GFP-MerE in suspension-cultured plant cells (B). GFP-tagged fusion proteins were expressed in suspension-cultured plant cells and viewed by confocal laser scanning microscopy. GFP fluorescence images are shown for GFP-MerE (B). Bars $=20 \mu \mathrm{m}$. 


\section{A pMAE2}

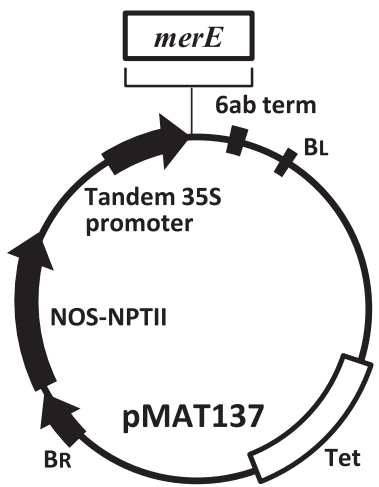

B Genome PCR

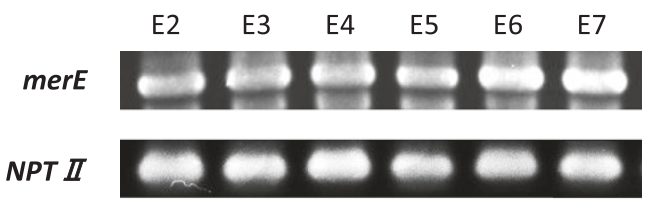

C RT-PCR

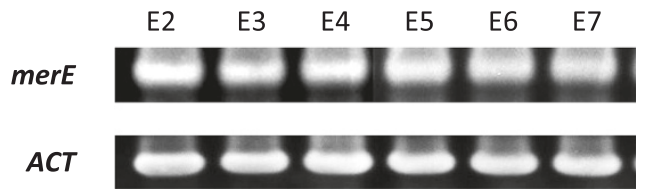

Figure $\mathbf{2}$ Characterization of merE in transgenic plant lines. The structure of the DNA region transferred using the plant expression plasmids pMAE2 (A). Confirmation of the expression of merE (E2, E3, E4, E5, E6, and E7) in transgenic plants based on genomic PCR expression analysis (B) Expression analyses of merE (E2, E3, E4, E5, E6, and E7) in transgenic plants, which were determined by reverse transcription PCR (C). Transgenic plants were grown on MS gellan gum plates. Plates were incubated at $22^{\circ} \mathrm{C}$ for 2 weeks. Genome DNA prepared from transgenic plants and used for genomic PCR analysis of merE (U-Not-merE and L-Xba-merE) and NPT II (U-321NPTII and L-1109NPTII). The total RNA was prepared from transgenic plants and used for reverse transcription PCR analysis to determine the merE (U-Not-merE and L-Xba-merE) and Actin (primer $\beta$-ACT-Fd and $\beta$-ACT-Rv) transcription levels.

\section{Effect of MerE expression on mercury accumulation and} mercury resistance in transgenic plants

Mercury accumulation was determined in transgenic Arabidopsis plants after exposure to $\mathrm{HgCl}_{2}$ or $\mathrm{CH}_{3} \mathrm{HgCl}$ in MS gellan gum plates for 2 weeks. After treatment with $10 \mu \mathrm{M} \mathrm{HgCl}_{2}$, the amount of mercury accumulated in the entire merE transgenic plants were higher than that in wild-type plants (Figure 4A). After treatment with $0.3 \mu \mathrm{M}$ $\mathrm{CH}_{3} \mathrm{HgCl}$, the amount of mercury accumulated in the entire merE transgenic plants were about 2-fold higher than that in the wild-type plants (Figure 4B).

The effect of MerE expression on mercury resistance was evaluated in transgenic Arabidopsis plants (lines E2) by monitoring the root and shoot growth of seedlings after exposure to $\mathrm{HgCl}_{2}$ or $\mathrm{CH}_{3} \mathrm{HgCl}$ in $\mathrm{MS}$ gellan gum plates for 2 weeks. In the absence of mercury, merE transgenic plants exhibited the same normal growth as wild-type Arabidopsis (Figure 5A). In the presence of $5 \mu \mathrm{M} \mathrm{HgCl}_{2}$ or $0.3 \mu \mathrm{M} \mathrm{CH} \mathrm{CH}_{3} \mathrm{HgCl}$, root and shoot growth

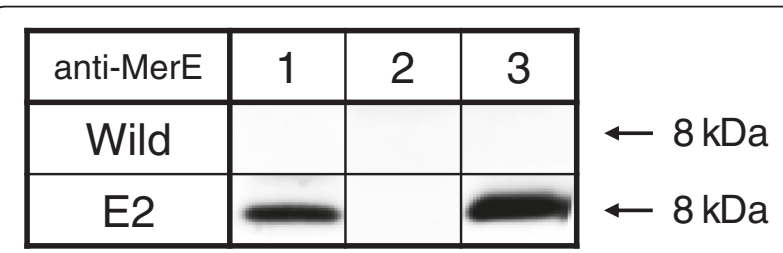

Figure 3 Immunoblot of MerE protein in transgenic plants. Immunoblot analysis of the crude cell extracts (lane 1), soluble fractions (lane 2), and membrane fractions (lane 3) obtained from wild type (Wild) and merE (E2) transgenic plants, which were performed using anti-MerE polyclonal antibodies. The amount of protein applied in each lane was $25 \mu \mathrm{g}$. The arrow indicates MerE (8 kDa). were inhibited in transgenic seedlings and wild-type Arabidopsis (Figure 5A). However, the shoot and root growth of the merE transgenic seedlings indicated significant tolerance compared with wild-type Arabidopsis in the presence of $5 \mu \mathrm{M} \mathrm{HgCl}$ (Figure $5 \mathrm{~A}-\mathrm{C}$ ). The shoot and root growth of merE transgenic seedlings also appeared to be better than that of wild-type Arabidopsis in the presence of $0.3 \mu \mathrm{M} \mathrm{CH} \mathrm{CH}_{3} \mathrm{HgCl}$ (Figure $5 \mathrm{~A}-\mathrm{C}$ ).

\section{Discussion}

Phytoremediation, using green plants to remove environmental pollutants including hazardous toxic metals removal from a large volume of contaminated sites is recognized as a cost-effective, sustainable and aesthetically pleasing technology (Tong et al. 2004). However, the use of plants, like all biological methods, does not allow 100\% removal of contaminants because the remediation rates decrease as the concentrations of contaminant decrease (Clemens et al. 2002). In addition, phytoremediation is a slow process that requires a long time to complete the purification (McGrath and Zhao 2003). These potential faults may predominantly result from the low metaluptake activity and thereby limit its usefulness for practical application.

Among the strategies being used to overcome these disadvantages is the use of metal transporter to boost the uptake and transport of metal from soil into transgenic plants (Song et al. 2003). Expression of heavy metal transporter or periplasmic $\mathrm{Hg}(\mathrm{II})$-binding protein genes under the control of a constitutive or inducible promoter may provide a means of improving metal uptake, thereby shortening the phytoremediation completion time (Kiyono et al. 2013; Kiyono et al. 2012; Nagata et al. 2009; 

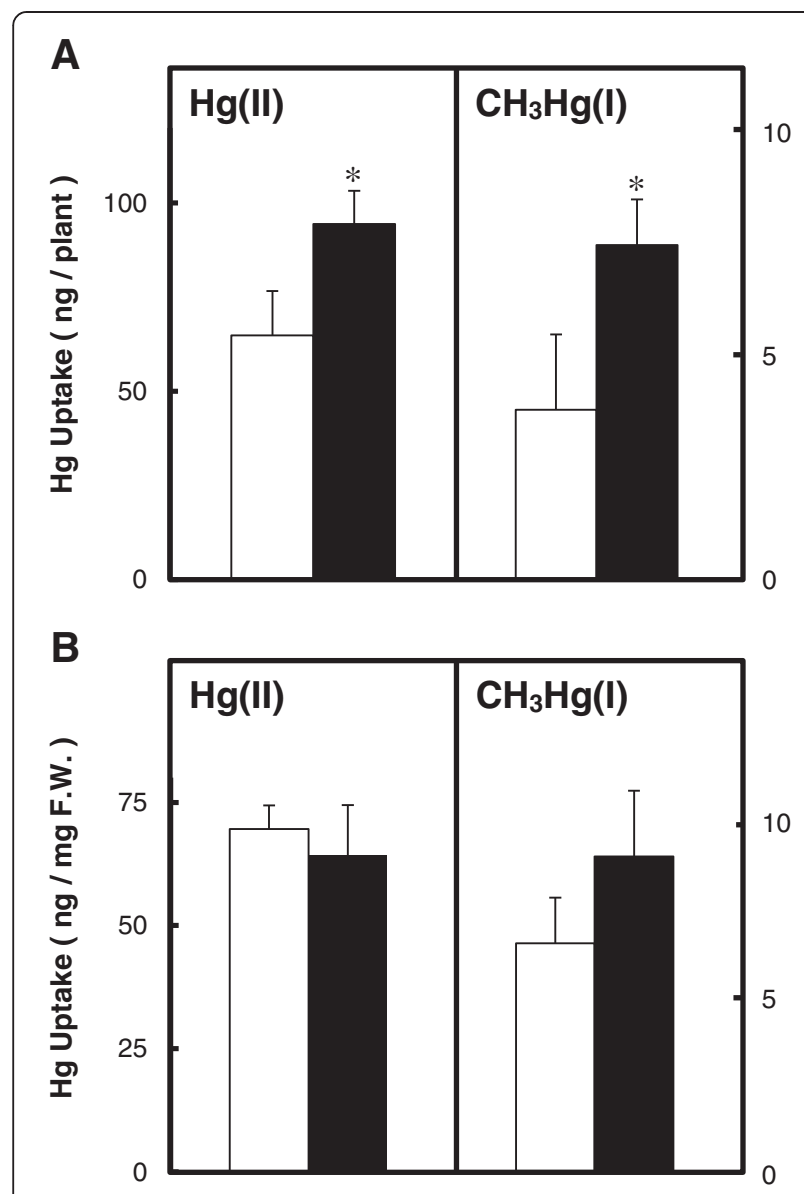

Figure 4 Accumulation of mercury from MS gellan gum plates containing $\mathrm{Hg}(\mathrm{II})$ and $\mathrm{CH}_{3} \mathrm{Hg}(\mathrm{I})$. The amounts of mercury $(\mathbf{A} ; \mathrm{ng} /$ plant, $\mathbf{B} ; \mathrm{ng}$ /fresh weight) that accumulated in wild-type plants (Wild; empty bar) and merE- transgenic plants (black bar) were determined after culture for 2 weeks on MS gellan gum plates with various concentrations of $\mathrm{HgCl}_{2}$ or $\mathrm{CH}_{3} \mathrm{HgCl}$, as described in the Materials and Methods. The data are expressed as the means \pm S.E. $M$. based on four determinations from three independent experiments. ${ }^{*} P<0.05$ vs. the wild type.

Hsieh et al. 2006). In the present study, a transgenic Arabidopsis plants engineered to express mercury transporter, MerE (Kiyono et al. 2009; Sone et al. 2010) was constructed and the impact of expression of MerE on methylmercury accumulation was evaluated.

By using the Agrobacterium-floral dip method, many independent transgenic Arabidopsis plants were obtained. The results obtained by genomic PCR (Figure 2B), RTPCR (Figure 2C) and immunoblot (Figure 3) analysis demonstrated that the $g f p$ tagged merE was successfully integrated into the genome of Arabidopsis plants and substantially transcribed into mRNA and then translated into the expected fusion proteins in the transgenic plants. Transgenic Arabidopsis plants expressing merE grew vigorously at rates similar to those of wild-type plants, without exhibiting notable symptoms of stress (Figure 5A).

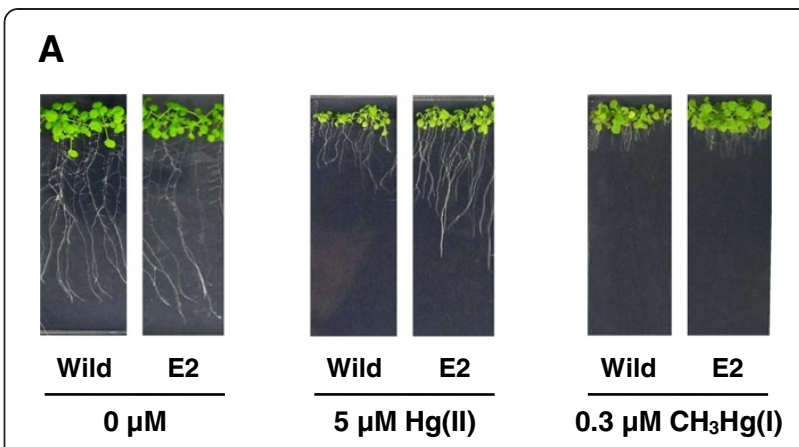

B
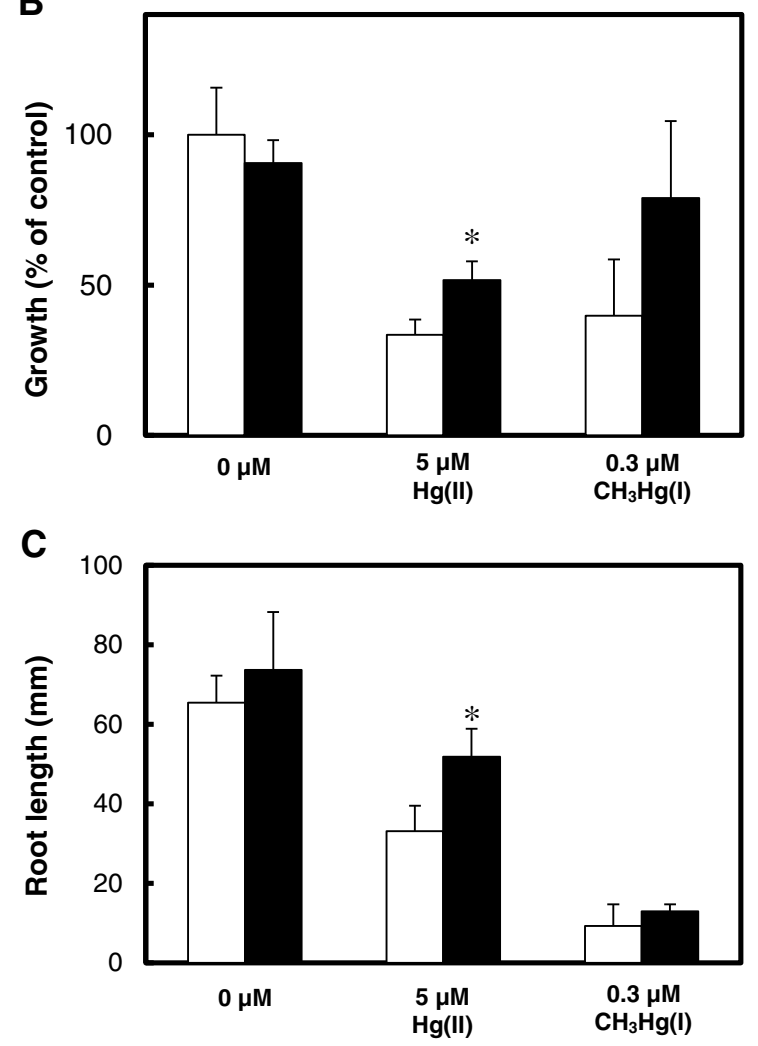

Figure 5 Susceptibility of transgenic plants to $\mathrm{Hg}(\mathrm{II})$ and $\mathrm{CH}_{3} \mathrm{Hg}$ (I). Sterilized seeds of wild-type (Wild) and transgenic (E2) plants were germinated and grown on MS gellan gum plates in the presence or absence of $5 \mu \mathrm{M} \mathrm{HgCl}_{2}$ and $0.3 \mu \mathrm{M} \mathrm{CH} \mathrm{CH}_{3} \mathrm{HgCl}$ (A). After culture for 2 weeks at $22^{\circ} \mathrm{C}$, the total wet weights of plants (B) and root growth (C) levels of wild-type plants (empty bar) and merEtransgenic plants (black bar) were evaluated as described in the Materials and Methods. The total wet weight of the wild-type plants in the absence of mercurials was considered as control (B). The data are expressed as the means \pm S.E.M. based on four determinations from three independent experiments. ${ }^{*} P<0.05$ vs. the wild type.

These results suggest that the integration of merE gene had no deleterious effects on the plant growth. The transgenic Arabidopsis expressing MerE accumulated significantly more $\mathrm{Hg}(\mathrm{II})$ and $\mathrm{CH}_{3} \mathrm{Hg}(\mathrm{I})$ than the wild-type Arabidopsis from the mercurial-containing medium (Figure 4). These results reveal that MerE is indeed 
functional as a broad-spectrum mercury transporter in transgenic Arabidopsis, and suggest that accelerated mercurials uptake into the plants mediated by MerE would provide one possible way for shortening the completion time of phytoremediation of mercury pollution.

Growth in a relatively higher concentration of mercurials and constitutive expression of mercury transport activity seem to be necessary for the plants applied in mercury remediation. The transgenic Arabidopsis displayed a relatively high level of $\mathrm{Hg}(\mathrm{II})$ and $\mathrm{CH}_{3} \mathrm{Hg}(\mathrm{I})$ resistance compared with the wild type (Figure 5). These results demonstrated that the toxic $\mathrm{Hg}(\mathrm{II})$ and $\mathrm{CH}_{3} \mathrm{Hg}(\mathrm{I})$ in the culture medium may have been transported into plant cells by the integrated merE and substantially inactivated in the cells by the physiological activity of the plant.

Phytoremediation is an effective and aesthetically pleasing technique for cleaning up soils contaminated with mercurials where excavation or bioremediation is not practical or possible (Heaton et al. 2003; Lyyra et al. 2007; Meagher and Heaton 2005). However, the technique is still in its infancy stage. This study showed that the expression of the bacterial mercury transporter MerE promoted the transport and accumulation of mercuric ions and methylmercury in transgenic Arabidopsis, which may be a useful method to facilitate the improvement of plants that could be applied to the phytoremediation of mercuric ions and methylmercury pollution. It is hoped that the efficiency of these newlydesigned transgenic Arabidopsis plants will be validated in field experiments in the near future.

\section{Competing interests}

The authors declare that they have no competing interests.

\section{Authors' contributions}

YS carried out the molecular studies, characterized transgenic plants, participated in analysis of mercury accumulation and resistant, and helped to prepare the manuscript. RN contributed valuable suggestions to the study. MHS carried out the cellular localization of GFP-MerE and supervised experimental design. HPH and TI supervised experimental design and revised the manuscript for submission. MK conceived and conducted the conception and design of the study and drafted the manuscript. All authors read and approved the final manuscript.

\section{Acknowledgments}

We thank Miss. Y. Oka, Mr. H. Tojo, Miss. M. Kaburagi and Miss. C. Kageyama for their technical assistance. This work was supported in part by a Grant-inAid for Young Scientists (B) (No. 24790128) to Y.S. and a Grant-in-Aid for Scientific Research (C) (No. 24510104) to M.K. from the Ministry of Education, Science and Culture, Japan.

\section{Author details \\ 'Department of Public Health and Molecular Toxicology, School of Pharmacy, Kitasato University, 5-9-1 Shirokane, 108-8641 Minato-ku, Tokyo, Japan. ${ }^{2}$ Faculty of Pharmaceutical Sciences, Setsunan University, 45-1 Nagaotoge- cho, 573-0101 Hirakata, Osaka, Japan. ${ }^{3}$ Graduate School of Life and Environmental Sciences, Kyoto Prefectural University, 1-5, Shimogamo- nakaragi-cho, 606-8522 Sakyo-ku, Kyoto, Japan.}

Received: 22 July 2013 Accepted: 29 August 2013

Published: 3 September 2013

\section{References}

Barkay T, Miller SM, Summers AO (2003) Bacterial mercury resistance from atoms to ecosystems. FEMS Microbiol Rev 27(2-3):355-384. doi:10.1016/s0168-6445 (03)00046-9

Bullock WO, Fernandez JM, Short JM (1987) XL1-Blue: a high efficiency plasmid transforming recA Escherichia coli strain with $\beta$-galactosidase selection. BioTechniques 5:376-379

Clemens S, Palmgren MG, Kramer U (2002) A long way ahead: understanding and engineering plant metal accumulation. Trends Plant Sci 7(7):309-315

Clough SJ, Bent AF (1998) Floral dip: a simplified method for Agrobacteriummediated transformation of Arabidopsis thaliana. Plant J 16(6):735-743

Harada M (1995) Minamata disease: methylmercury poisoning in Japan caused by environmental pollution. Crit Rev Toxicol 25(1):1-24. doi:10.3109/ 10408449509089885

Heaton AC, Rugh CL, Kim T, Wang NJ, Meagher RB (2003) Toward detoxifying mercury-polluted aquatic sediments with rice genetically engineered for mercury resistance. Environ Toxicol Chem 22(12):2940-2947

Hsieh JL, Chen CY, Chiu MH, Chein MF, Chang JS, Endo G, Huang CC (2006) Expressing a bacterial mercuric ion binding protein in plant for phytoremediation of heavy metals. J Hazard Mater 161(2-3):920-925. doi:10.1016/j.jhazmat.2008.04.079

Kiyono M, Sone Y, Nakamura R, Pan-Hou H, Sakabe K (2009) The MerE protein encoded by transposon Tn21 is a broad mercury transporter in Escherichia coli. FEBS Lett 583(7):1127-1131. doi:10.1016/j.febslet.2009.02.039

Kiyono M, Oka Y, Sone Y, Tanaka M, Nakamura R, Sato MH, Pan-Hou H, Sakabe K, Inoue K (2012) Expression of the bacterial heavy metal transporter MerC fused with a plant SNARE, SYP121, in Arabidopsis thaliana increases cadmium accumulation and tolerance. Planta 235(4):841-850. doi:10.1007/ s00425-011-1543-4

Kiyono M, Oka Y, Sone Y, Nakamura R, Sato MH, Sakabe K, Pan-Hou H (2013) Bacterial heavy metal transporter MerC increases mercury accumulation in Arabidopsis thaliana. Biochem Eng J 71:19-24. doi:10.1016/j. bej.2012.11.007

Kramer U (2005) Phytoremediation: novel approaches to cleaning up polluted soils. Curr Opin Biotechnol 16(2):133-141. doi:10.1016/j. copbio.2005.02.006

Lyyra S, Meagher RB, Kim T, Heaton A, Montello P, Balish RS, Merkle SA (2007) Coupling two mercury resistance genes in Eastern cottonwood enhances the processing of organomercury. Plant Biotechnol J 5(2):254-262. doi:10.1111/ j.1467-7652.2006.00236.x

Malik A (2004) Metal bioremediation through growing cells. Environ Int 30(2):261-278. doi:10.1016/j.envint.2003.08.001

Matsuoka K, Nakamura K (1991) Propeptide of a precursor to a plant vacuolar protein required for vacuolar targeting. Proc Natl Acad Sci USA 88(3):834-838

McGrath SP, Zhao FJ (2003) Phytoextraction of metals and metalloids from contaminated soils. Curr Opin Biotechnol 14(3):277-282

Meagher RB, Heaton AC (2005) Strategies for the engineered phytoremediation of toxic element pollution: mercury and arsenic. J Ind Microbiol Biotechnol 32(11-12):502-513. doi:10.1007/s10295-005-0255-9

Mozo T, Hooykaas PJ (1991) Electroporation of megaplasmids into Agrobacterium. Plant Mol Biol 16(5):917-918

Nagata T, Nakamura A, Akizawa T, Pan-Hou H (2009) Genetic engineering of transgenic tobacco for enhanced uptake and bioaccumulation of mercury. Biol Pharm Bull 32(9):1491-1495. doi:10.1248/bpb.32.1491

Nakano A (2002) Spinning-disk confocal microscopy - a cutting-edge tool for imaging of membrane traffic. Cell Struct Funct 27(5):349-355

Ruiz ON, Daniell H (2009) Genetic engineering to enhance mercury phytoremediation. Curr Opin Biotechnol 20(2):213-219. doi:10.1016/j. copbio.2009.02.010

Salt DE (1998) Arboreal alchemy. Nat Biotechnol 16(10):905. doi:10.1038/nbt1098-905

Sone Y, Pan-Hou H, Nakamura R, Sakabe K, Kiyono M (2010) Roles played by MerE and MerT in the transport of inorganic and organic mercury compounds in Gram-negative bacteria. J Health Sci 56(1):123-127

Song WY, Sohn EJ, Martinoia E, Lee YJ, Yang YY, Jasinski M, Forestier C, Hwang I, Lee $Y$ (2003) Engineering tolerance and accumulation of lead and cadmium in transgenic plants. Nat Biotechnol 21(8):914-919. doi:10.1038/ nbt850

Tong YP, Kneer R, Zhu YG (2004) Vacuolar compartmentalization: a secondgeneration approach to engineering plants for phytoremediation. Trends Plant Sci 9(1):7-9 

type Rab GTPase, functions in the endocytic pathway of Arabidopsis thaliana. EMBO J 20:4730-4741

Uemura T, Ueda T, Ohniwa RL, Nakano A, Takeyasu K, Sato MH (2004) Systematic analysis of SNARE molecules in Arabidopsis: dissection of the post-Golgi network in plant cells. Cell Struct Funct 29(2):49-65

doi:10.1186/2191-0855-3-52

Cite this article as: Sone et al: Increase methylmercury accumulation in

Arabidopsis thaliana expressing bacterial broad-spectrum mercury

transporter MerE. AMB Express 2013 3:52.

Submit your manuscript to a SpringerOpen ${ }^{\circ}$ journal and benefit from:

- Convenient online submission

- Rigorous peer review

- Immediate publication on acceptance

- Open access: articles freely available online

- High visibility within the field

- Retaining the copyright to your article

Submit your next manuscript at $\gg$ springeropen.com 